\title{
Ultrasonic Determination of Recrystallization
}

\author{
(NASA-TM-88855) ULTRASCNIC DETEBMINATION OF \\ EECRYSTALLIZATICN (NASA) $15 \mathrm{~F}$ CSCL 14D
}

N $87-10399$

Unclas

G3/38 44241

Edward R. Generazio

Lewis Research Center

Cleveland, Ohio

Prepared for

Review of Progress in Quantitive NDE

cosponsored by Ames Laboratory and Iowa State University

La Jolla, California, August 3-8, 1986

\section{N/Sก}




\title{
ULTRASONIC DETERMINATION OF RECRYSTALLIZATION
}

\author{
Edward R. Generazio \\ National Aeronautics and Space Administration \\ Lewis Research Center \\ Cleveland, $\mathrm{OH}$.
}

\section{INTRODUCTION}

Metals are currently used in a wide variety of applications ranging from simple structural to complex heat engine components. Each use has a different set of engineering characteristics that must be met by the material being considered for use. One method to tallor material properties to meet engineering requirements is thermomechanical processing (TMP). 1,2 If TMP involves cold working, metals generally show a marked increase in strength, but this increase does not continue without limit as the microstructure becomes distorted and exhibits high internal stress. These residual stresses are generally detrimental to the end use applications.

Further modification of the material can be obtained by annealing the material at various intervals during the cold working process. Annealing serves two ma in purposes. (1) To relax residual stresses and (2) to recrystallize (soften) the material. Stress relieving results in partial softening due to the movement and annihilation of dislocations 3,4 while recrystalization yields a total softening by the complete replacement of the worked microstructure with an essentially dislocation free new grain structure. Both of these processes are dependent on the amount of prior cold work, temperature, and time where the time to complete the process decreases as the amount of work or temperature increases.

In the case of recrystallization there are several experimentally measurable material properties that exhibit marked variations. Four of the most common material characteristics $1-3$ are hardness, strength, ductility, and microstructural changes. The experimental signatures of each of these after recrystallization are (1) the material hardness decreases, (2) the yield strength decreases, (3) the ductility increases, and (4) a free grain structure appears. While these changes can be observed by mechanically testing, and metallographic, diffractive $x$-ray and transmission electron microscopic examination, generally destructive testing methods are required.

It is shown here that the nondestructive measurement of ultrasonic attenuation can identify and characterize the state of the recrystallization. The interrelation between ultrasonic attenuation and recrystallization thermal kinetics yields a technique for determining onset, degree, and completion of recrystallization. 
We are concerned here with the ultrasonic interaction with material microstructure and the thermal process of recrystallization. Two theories covering acoustic-microstructure ${ }^{5-7}$ interaction and the thermal kinetics of recrystallization 8-10 need to be examined. It is assumed that the acoustic interaction with the microstructure is dominated by grain scattering 6 and/or dis location damping. 7 other acoustic-microstructural interactions leading to magnetoelastic and thermoelastic effects 5 are not expected to change substantially and/or concurrently with recrystallization.

The attenuation ag due to grain scattering is given by 6 $a_{r}=C_{r} D^{3} F^{4}$ (Rayleigh) and $a_{s}=C_{s} D F^{2}$ (Stochastic)

where the C's are constants dependent on density, velocity, etc., $D$ is the mean grain diameter, $F$ is frequency. When the wavelength of sound is much greater than the mean grain diameter or scatterer size, we have Rayleigh scattering with a fourth power frequency dependence. When the scatterer size is on the order of the sound wavelength we have stochastic scattering with a second power frequency dependence. Equation (1) should not be expected to apply to an arbitrary metal consisting of a size distribution of topologically complex grains. However, we may identify the frequency exponent as a key variable. That is, if grains are growing from small (Rayleigh) to large (stochastic) scatterers is is expected that the frequency exponent, over a fixed frequency range, should decrease with increasing grain size.

The attenuation due to dislocation damping ad is given by 7

$a_{d}=g C W\left(F, F_{0}\right)$

where $g$ is the dislocation density, $C$ is a constant dependent on shear modulus, dislocation damping force, etc., and $W$ is a complicated function of the resonant frequency $F_{0}$. Equation (2) applies to materials containing a dilute noninteracting collection of dislocation lines or ented normal to the sound direction. Equation (2) does not apply to the intertwined network of dislocations observed in mechanically worked materials. Equation (2) does, however, imply that if dislocation damping is dominant attenuation mechanism then a decrease in dislocation density should result in a corresponding decrease in attenuation.

\section{THERMAL KINETICS}

Mechanically working a metal produces a dense collection of germ nuclel within the material. These germ nuclei, when activated by an increase in temperature, transform (i.e., recrystallize) into small crystallites which subsequently grow into fully developed grains. The transformed volume is given by $8-10$

$\frac{V_{R}}{V}=\sum_{i=1}^{M}\left\{1-\exp \left[-S G^{3} N_{0} t^{3} \exp \left(-\frac{U}{R T_{i}}\right)\right]\right\}$

where $V_{R}$ is the volume that has recrystallized and $V$ is the initial unrecrystallized volume, and 
$S$ shape factor

$G$ grain growth rate

$R$ gas constant

$N_{0}$ initial number of germ nuclei per unit volume

$U$ total energy required for a germ nuclei to become a growth nucleus (crystallite)

$T_{i}$ absolute anneal temperature

$t$ anneal time

Equation (3) is applicable to thermal annealing processes, where the time of each anneal is held constant and the anneal temperature $T_{j}$ is varied for a series of $M$ anneals.

Although $G, U, S$, and $N_{0}$ are known to vary with temperature, $1,3,4,8-10$ the value of these parameters as a function of temperature is unknown. It will be assumed that they are constants and this should be considered when using the thermal kinetic results.

Material Samples

The samples were produced from commercially available Nickel 200 rod that has been initially cold rolled 50 percent and annealed at $631 \pm 5 \mathrm{~K}$ for $15 \mathrm{~min}$, then cold rolled an additional 50 percent. Four samples for ultrasonic evaluation were cut from the rolled material with both sides ground and polished through $1.0 \mu \mathrm{m}$ diamond to a mirror finish. Thirtytwo specimens for metallographic, $x$-ray, and transmission electron microscopic analysis were also cut from the rolled stock.

\section{Experiment}

The 36 specimens (anneal batch) were initially simultaneously annealed as a group in air at $758 \mathrm{~K}$ for $1 \mathrm{hr}$ and air cooled. Two metallography specimens were selected and permanently removed from the group for microstructural, $x-r a y$, and transmission electron microscopic evaluation, and the four polished samples were remeasured for thickness and ultrasonic attenuation ( 30 to $65 \mathrm{MHz}$ ). 11 After ultrasonic investigation these four samples and the remaining 30 specimens were heat treated at a higher temperature. This process of specimen selection (permanent removal of two specimens) and ultrasonic evaluation of the four polished samples was repeated 16 times with the annealing temperature increased for each step and ranging from 758 to $1011 \mathrm{~K}( \pm 5 \mathrm{~K})$. The two specimens removed after each step were investigated using: (1) metallography to determine microstructural changes, (2) transmission electron microscopy to identify dislocation density variations, and (3) x-ray diffraction to determine crystalline disorder.

\section{Microstructure}

Three mutualiy perpendicular faces of the annealed samples were polished, etched, and photographed using standard metallographic procedures.

Three millimeter diameter, $0.38 \mathrm{~mm}$ thick disks were electro-discharge machined (EDM) from the annealed specimens. After the disks were hand ground to a thickness of about $0.002 \mathrm{~cm}$ and further electropolished to a thickness of about $800 \AA$, they were examined by transmission electron microscopy (TEM). At least three TEM disks were examined for each annealing temperature. 


\section{Ultrasonic Attenuation}

The ultrasonic attenuation as a function of frequency for each of the annealing temperatures is shown in Fig. 1 and the attenuation for fixed frequency is 11 lustrated as a function of anneal temperature in Fig. 2. While the attenuation for all temperatures increases with increasing frequency, the attenuation for constant frequencies, is observed to be a nonmonotonic function of the anneal temperature (Fig. 2). Below $800 \mathrm{~K}$ the attenuation (for fixed frequency) remains constant. The attenuation increases rapidly with temperature from 800 to $900 \mathrm{~K}$. Although the attenuation continues to increase between 900 and $975 \mathrm{~K}$ it is at a much slower rate. Above $975 \mathrm{~K}$ the attenuation again rapidly rises with temperature. Figure 2 also demonstrates that the magnitude of the variation in attenuation over the entire anneal temperature range is more pronounced at higher frequencies.

\section{X-Ray Analysis}

The full width at half maximum (FWHM) of the (200) x-ray Bragg peak varies considerably over the annealing temperature range (Fig. 2). For temperatures below $850 \mathrm{~K}$ the FWHM remains relatively constant. The FWHM rapidly decreases over the range 850 to $900 \mathrm{~K}$. This is an indication of increasing crystalline order with increasing anneal temperature. Temperatures above $901 \mathrm{~K}$ resulted in a relatively constant FWHM. The uncertainty in this measurement is relatively large as evidenced by the fluctuating FWHM at both low and high anneal temperatures.

\section{Metallographic Results}

Typical photomicrographs for the face and edge sides are shown in Figs. 3 to 8 for anneal temperatures of $758,814,871,901,940$, and $1011 \mathrm{~K}$ (labeled $T_{7}-T_{6}$ ), respectively. As the the two perpendicular edges exhibited similar microstructure, only data for one edge is shown.

Photomicrographs of the face plane 1llustrate little change with annealing temperature until it equaled approximately $901 \mathrm{~K}$ where the unclear, worked structure remaining after lower temperature heat treatments (Figs. $3(\mathrm{c}), 4(\mathrm{c})$, and $5(\mathrm{c})$ ) is replaced by a normal grain structure (Fig. 6(c)). Higher annealing temperatures (Figs. $7(\mathrm{c})$ and $8(\mathrm{c})$ ) result in little additional change except for grain growth. While examination of the face sections reveals a sharp transition in microstructure at $901 \mathrm{~K}$, the edge planes show a much more gradual effect. As the annealing temperature is increased above $871 \mathrm{~K}$ the elongated grain structure visible in Figs. $3($ b) and $4(b)$ is slowly replaced by a normal grain configuration (Figs. $5($ b) and $6(b)$ ) until recrystallization is nearly complete (Fig. $7(b)$ ) and grain growth occurs (Fig. $8(b)$ ).

\section{Transmission Electron Microscopy}

Transmission electron photomicrographs for six anneal temperatures are also shown in Flgs. 3 to 8 . Below $800 \mathrm{~K}$ TEM found only localized areas with high and low dislocation densities (Fig. 3(a)). The high and low density regions are dark and light areas, respectively, in Fig. 3. At $814 \mathrm{~K}$, nucleated crystallites have started to form (Fig. 4(a)) with the nucleated crystallites varying in size and exhibiting boundaries constructed of an intertwined collection of dislocations. Figure 4 also contains regions that appear to be just forming into crystallites; these regions are believed to be germ nuclei that have just transformed into 
nucleation sites. At $871 \mathrm{~K}$ fully developed crystallites with planar boundaries co-exist with localized regions of low and high dislocation densities (Fig. 5(a)). The $901 \mathrm{~K}$ anneal exhibits larger crystallites having both narrow step-like boundaries and boundaries containing a collection of oriented dislocation plle-ups (Fig. 6(a)); additionally, isolated and interconnected dislocations are present within the crystallites. After a $940 \mathrm{~K}$ anneal ( $\mathrm{Fig} .7(\mathrm{a})$ ) the boundaries tend to have a collection of dislocations randomly attached to them, and both isolated and interconnected dislocations are present within the crystallites. At the highest anneal temperature, $1011 \mathrm{~K},(\mathrm{Fig} .8(\mathrm{a})$ ), only random isolated dislocations are present within the crystallites.

\section{Correlation Between Ultrasonic Attenuation and Thermal Kinetics}

Figure 9 shows the value of the key variable $N$ (dashed-dotted curve) determined by fitting the data shown in $\mathrm{Fig} .1$ to

$a=C F^{N}$

The percent of recrystalization $V_{R} / V$ determined by use of Eq. (3) is shown as a solid curve. Here $S=4 \pi / 3, G=3 \mu \mathrm{m} / \mathrm{hr}, U=80 \mathrm{Kcal} /$ mole $3,8-10$ and the free parameter $N_{0}$ is taken to be $2 \times 10^{18}$ germ nuclei/ $\mathrm{cm}^{3}$. Also shown is the percent of recrystallization, obtained from the photomicrographs, 9 for samples exhibiting about 25 to 75 percent recrystallization; larger and smaller percents could not be precisely determined by optical methods.

\section{DISCUSSION}

During the entire annealing process the attenuation at a fixed frequency either remains constant or increases with increasing anneal temperature. The dislocation density is not known quantitatively, it does, however, decrease from an extremely large to a low value as recovery and recrystallization takes place over the anneal temperature range. Therefore, dislocation damping cannot be the dominant attenuation mechanism causing the large change in attenuation observed during recrystaliization. From this result it will be assumed that the grain boundary scattering is the dominant attenuation mechanism during the recrystallization process.

The onset of recrystallization is identified as the temperature at which the first germ nuclei transform into nucleated crystallites. Acoustically the onset of recrystallization begins in the temperature range 796 to $814 \mathrm{~K}$ where the attenuation first starts to increase (1ight shaded region in $\mathrm{Fig} .10$ ). At these anneal temperatures the small nucleated crystallites are acoustically Rayleigh scatterers yielding the large value of the exponent $N$ (Fig. 9).

Increasing the anneal temperature produces an increasing number of nucleated crystallites and simultaneousiy enhances the growth rate of previously nucleated crystallites. Therefore, above $814 \mathrm{~K}$ there is a mixed system of Rayleigh (newly formed crystailites) and nearly stochastic (growing crystallites) scatterers. For temperatures between 814 and $975 \mathrm{~K}$, the magnitude of the attenuation is expected to increase while the exponent $N$ should decrease (see Eq. (1)). This is in agreement with Figs. 2 and 9 and is identified as the recrystallization temperature range in Fig. 10 (dark shaded region).

The completion of recrystallization is identified as the temperature at which all the germ nuclei are depleted. That is, the germ nuclei have 
either transformed into nucleated crystallites or have been swallowed up by growing crystallites. The completion of recrystallization occurs between 960 and $975 \mathrm{~K}$ and is shown in Fig. 10 as a light shaded region.

Above $975 \mathrm{~K}$ pure grain growth is observed (cross-hatched region in Fig. 10). Since the grains are relatively large (approximately $50 \mu \mathrm{m}$ diameter), for temperatures above $975 \mathrm{~K}$, they (growing at rate of about $3 \mu \mathrm{m} / \mathrm{hr}$ ) are stochastic scatterers; thus the attenuation above $975 \mathrm{~K}$ should increase while the exponent $N$ should remain a constant (Eq. (1)) in agreement with Figs. 2 and 9 . It should be noted here, that the attenuation in the pure grain growth region has been investigated previously 73 and found to scale with the ratio of mean grain diameter to sound wavelength indicating that dominant attenuation mechanism is grain boundary scattering.

Both the recrystallized function $V_{R} / V$ and the exponent $N$ possess similar temperature dependence (Fig. 9). The thermal kinetic results supports the attenuation data and is understood as follows. The probability of a germ nuclei transforming into a nucleated crystallite increases with increasing anneal temperature. Therefore, an initially slow recrystalization rate is followed by a rapid increase in the rate. Also, the germ nuclei transform simultaneously with the growth of previous nucleated crystallites. These growing crystallites tend to swallow up other germ nuclei so that the density of germ nuclei decreases. Therefore, there are two mechanisms that lead to a decrease in germ nuclei density. The germ nuclei become activated and transform into crystallites or they get swallowed up by growing crystallites. As a result the recrystallization rate (or the rate of formation of Rayleigh scatters) at high temperatures decreases.

A direct analogy exists between the recrystallization rate and the reaction rate observed in many chemical processes. This follows from the shape of the attenuation versus annealing temperature data. Moving from the left to the right in Fig. 10 we see an increase in the attenuation with a simultaneous increase in slope. This region is commensurate with a rapid transformation of germ nuclei to nucleated crystallites (Rayleigh scatterers). Above $901 \mathrm{~K}$, the slope of the attenuation begins to decrease. This agrees with a large number of germ nuclei being swallowed up by growing crystallites (i.e., a decreased rate of Rayleigh scatterer formation). The slope of the attenuation begins to increase rapidly once more above $975 \mathrm{~K}$. This is a signature that the recrystallization process has completed (1.e., germ nuclei are depleted) and only pure grain is growth present. Therefore, onset, percent, and completion of recrystalization (or onset of pure grain growth) are all identifiable from the ultrasonic attenuation as shown in Fig. 10.

The magnitude of the FWHM of a Bragg peak is dependent on several mechanisms.2,12 When residual stresses are present the atoms are displaced from their lattice sites and this results in a broadening of the Bragg peak. It is also possible to have crystallites with similar but not identical orientation within the area covered by the $x$-ray beam. This will also lead to a broadening of the Bragg peak. The presence of dislocations results in high localized stresses and large displacements of atoms from their otherwise ordered crystalline structure. These large atomic displacements will lead to a broadening of the Bragg peak.

The FWHM of the diffraction peak obtains a minimum value at $901 \mathrm{~K}$. This is an indication that the highest crystalline order has been obtained. However, the edge photomicrographs clearly indicate that recrystallization is incomplete (Fig. 6(b)). Bragg backscattered x-rays 
probe only a few microns, so that, the FWHM diffraction data indicates that the surface of the sample has recrystallized at $901 \mathrm{~K}$. This is optically supported by comparing Fig. 5(b) and (c) with fig. $6(b)$ and (c).

Because TEM specimens are quite small, it is difficult to characterize the extent of any reaction without preparing and studying a large number of specimens. Even when a sufficient group is analyzed, questions can remain due to the uncertainties involved in the electrochemical thinning procedures. However, identification of small crystallites after $814 \mathrm{~K}$ anneal signifies that recrystallization has started at this temperature which is significantly below the minimum temperature (approximately $871 \mathrm{~K}$, Fig. 5(b)) estimated from the optical metallographic evidence.

\section{CONCLUSION}

UTtrasonic attenuation was measured for cold worked Nickel 200 samples annealed at increasing temperatures. Localized dislocation density variations, crystalline order, and volume percent of recrystallized phase were examined over the annealing temperature range using transmission electron microscopy, x-ray diffraction, and metallography. The exponent of the frequency dependence of the attenuation has been found to be a key variable relating ultrasonic attenuation to the thermal kinetics of the recrystallization process. Measurement of this key variable allows for the ultrasonic determination of onset, degree, and completion of recrystallization.

$X$-ray, metallography, and TEM analysis individually cannot characterize the state of the recrystallization process. However, the ultrasonic attenuation, being extremely sensitive to the formation of small scatterers and having a wide dynamic range to large scatters, is able to characterize the recrystallization process.

\section{REFERENCES}

1. R.E. Reed-Hill, "Physical Metallurgy Principles," 2nd ed., Van Nostrand, New York, 1973.

2. G.E. Dieter, "Mechanical Metallurgy," McGraw-Hill, New York, 1961.

3. L.M. Clarebrough, M.E. Hargreaves, and G.W. West, Proceedings of the Royal Society, Part A, 232, 252-270 (1955).

4. J.F. Nicholas, Philosophical Magazine, 46, 87-97 (1955).

5. R. True11, C. Elbaum, and B.B. Chick, "Ultrasonic Methods in Solid State Physics," Academic Press, NY, 1969.

6. E.P. Papadakis, Journal of the Acoustical Society of America, 37, $711-717$ (1965).

7. A. Granato and K. Lucke, Journal of Applied Physics, 27, 583-593 (1956).

8. M. Avrami, Journal of Chemical Physics, I, 1103-1112 (1939).

9. M. Avrami, Journal of Chemical Physics, 8 , 212-224 (1940).

10. M. Avrami, Journal of Chemical Physics, 9, 177-184 (1941).

11. E.R. Generazio, Materials Evaluation, 43, 995-1004 (1985). 
12. P. Gay; P.B. Hirsch, and A. Kelly, Acta Metallurgica, I, 315-319 (1953).

13. E.R. Generaz1o, Materials Evaluation, 44, 198-202, 208 (1986). 


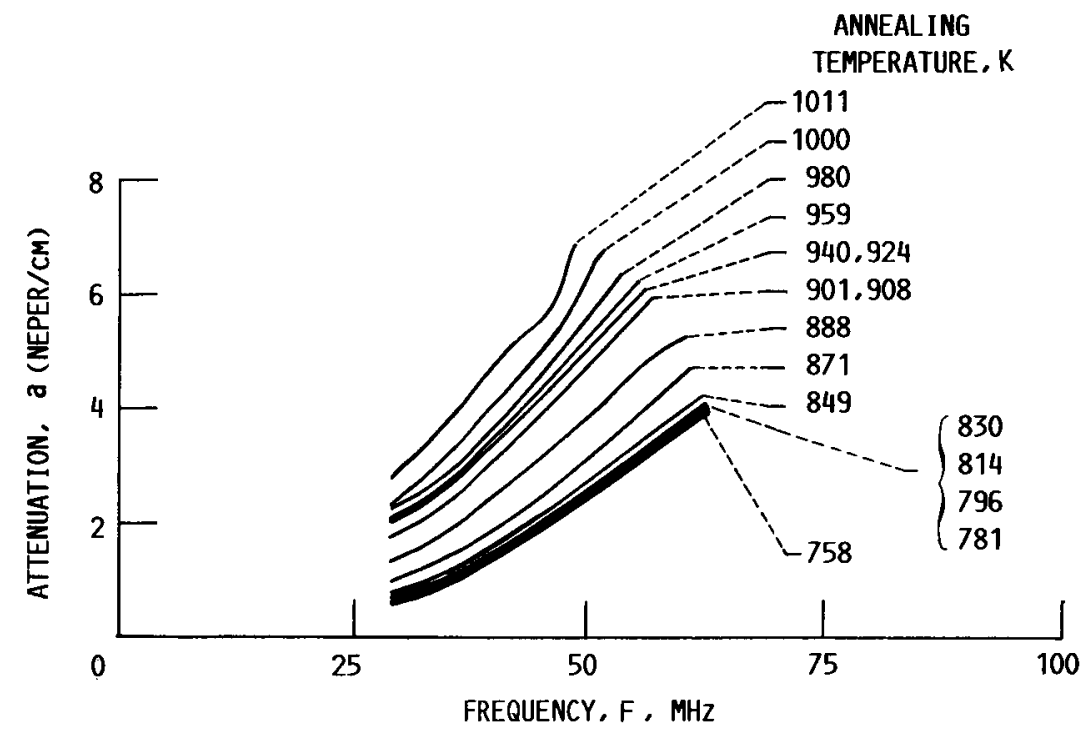

FigURE 1. - ULTRASONIC ATTENUATION AS A FUNCTION OF FREQUENCY.

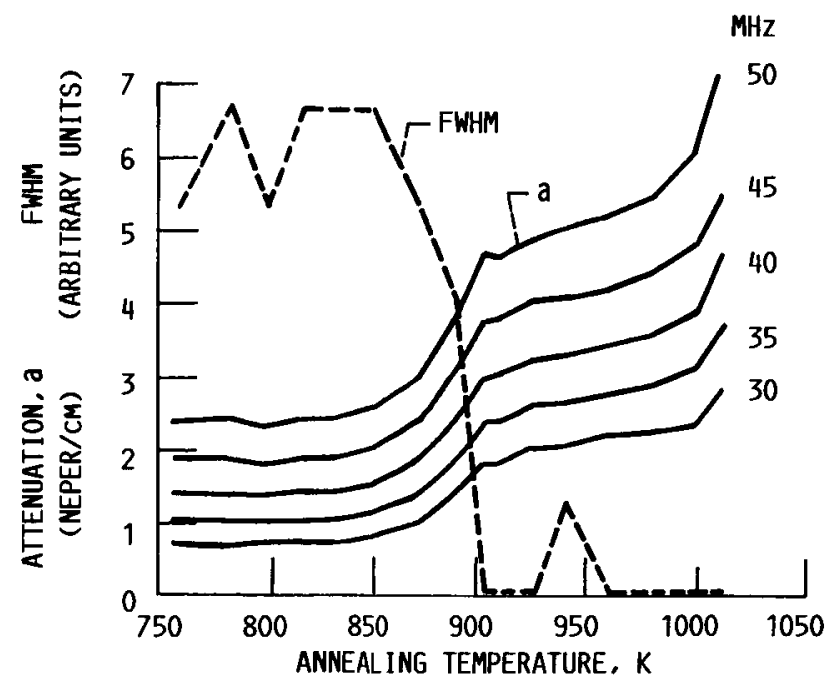

Figure 2. - ULTRASONIC ATTENUATION AS A FUNCTION OF ANNEAL TEMPEATURE (SOL ID CURVES). THE DASH CURVE IS THE FULL WIDTH AT HALF MAXIMUM OF THE $\left(\begin{array}{lll}2 & 0 & 0\end{array}\right) \times$-RAY DIFFRACTION PEAK. 

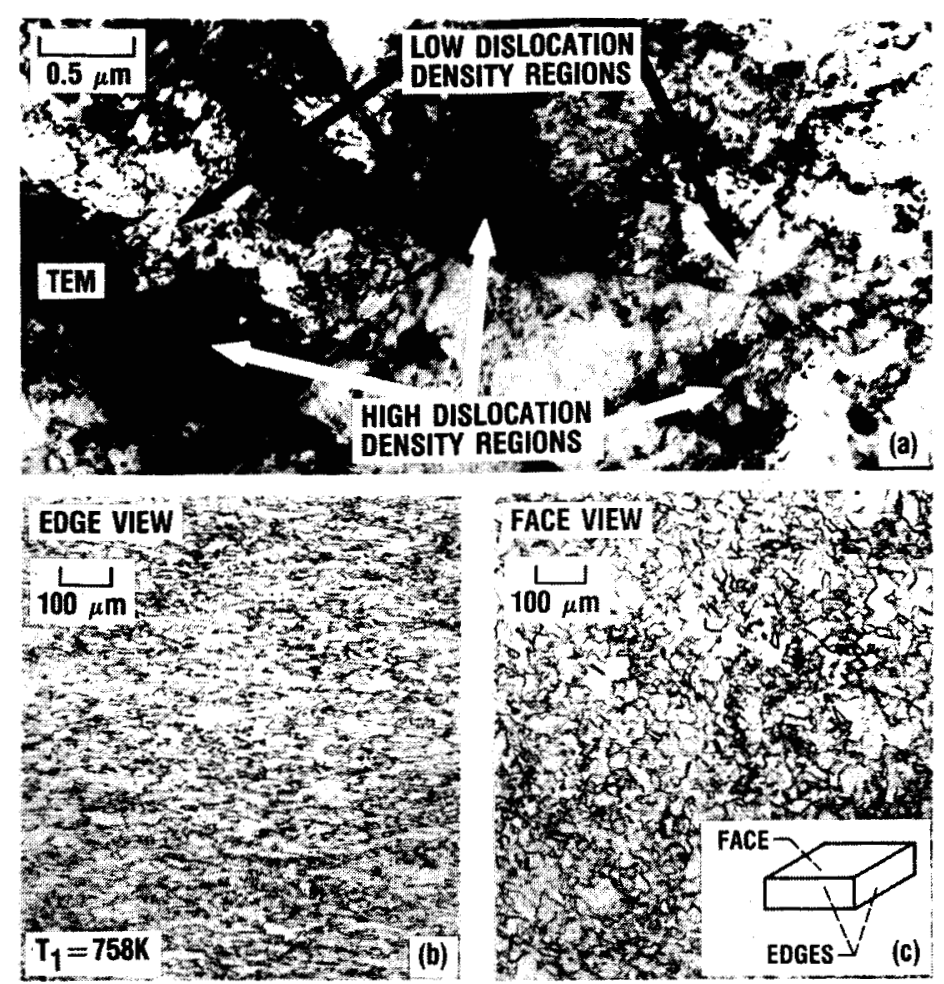

FIgURE 3. - TRANSMISSION ELECTRON MICROGRAPH, AND EDGE AND SIDE METALLOGRAPHIC VIEWS OF SAMPLE ANNEALED AT $758 \mathrm{~K}\left(\mathrm{~T}_{1}\right)$.

ORIGINAL FAGE SS OF POOR QUALTY
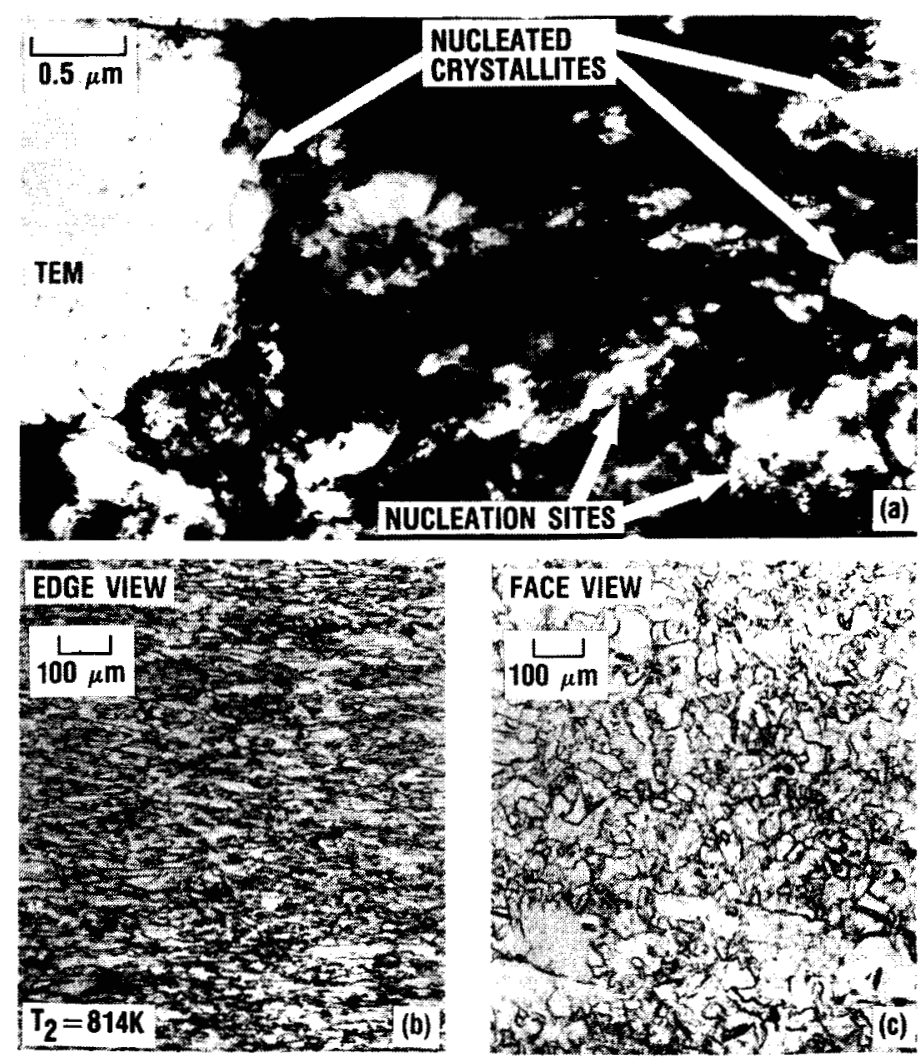

Figure 4. - TRANSMISSION ELECTRON MICROGRAPH, AND EDGE AND SIDE METALLOGRAPHIC VIEWS OF SAMPLE ANEALED AT $814 \mathrm{~K}\left(\mathrm{~T}_{2}\right)$. 


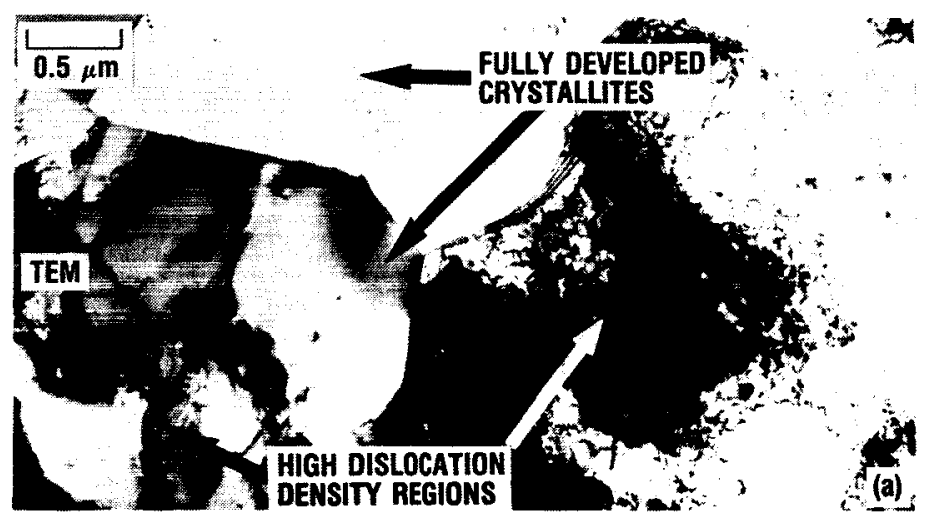

\section{ORIGINAL PAGE KS
OF POOR QUALTYY}

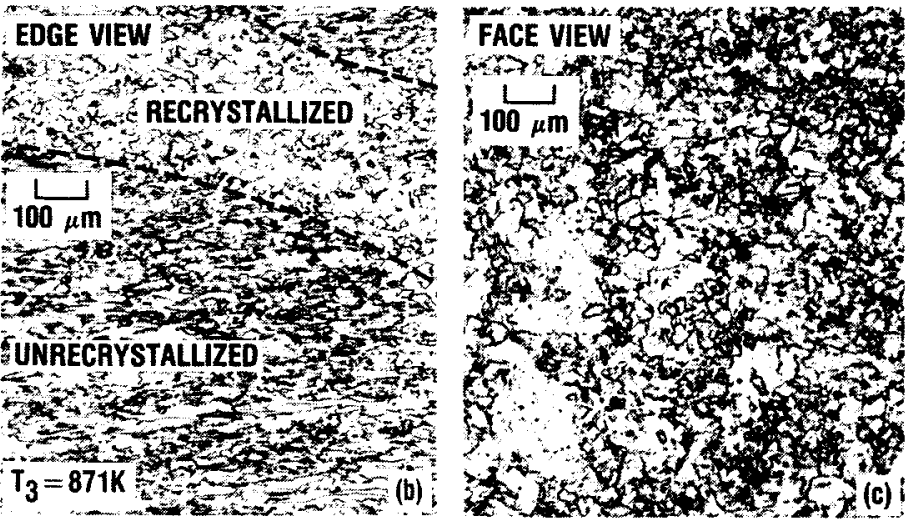

Figure 5. - TRANSMISSION ELECTRON MICROGRAPH, AND EDGE AND SIDE METALLOGRAPHIC VIEWS OF SAMPLE ANNEALEd AT $871 \mathrm{~K}\left(\mathrm{~T}_{3}\right)$.
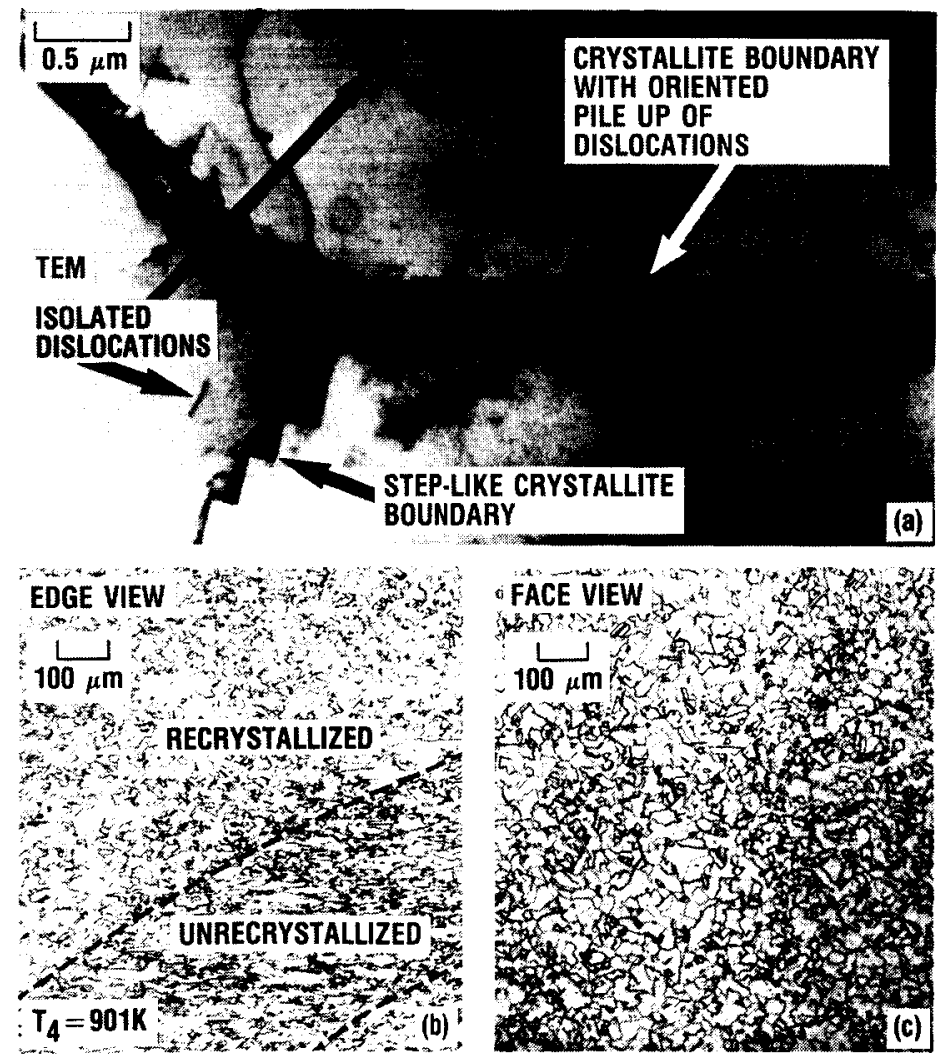

FIGURE 6. - TRANSMISSION ELECTRON MICROGRAPH, AND EDGE AND SIDE METALLOGRAPHIC VIEWS OF SAMPLE ANNEALED AT $901 \mathrm{~K}\left(\mathrm{~T}_{4}\right)$. 

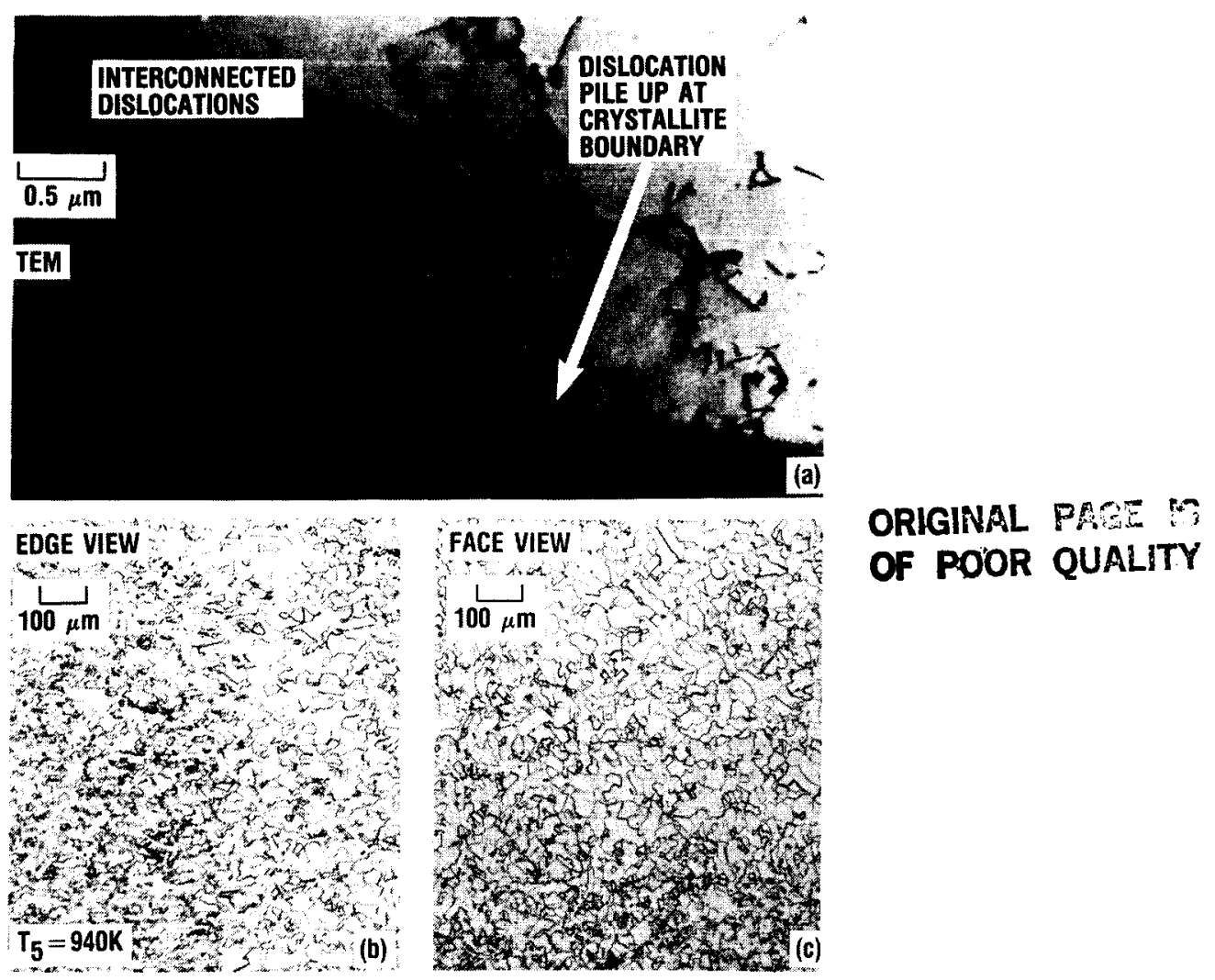

Figure 7. - TRANSMISSION ELECTRON MICROGRAPH, AND EDGE AND SIDE METALLOGRAPHIC VIEWS OF SAMPLE ANNEALED AT $940 \mathrm{~K}\left(\mathrm{~T}_{5}\right)$.

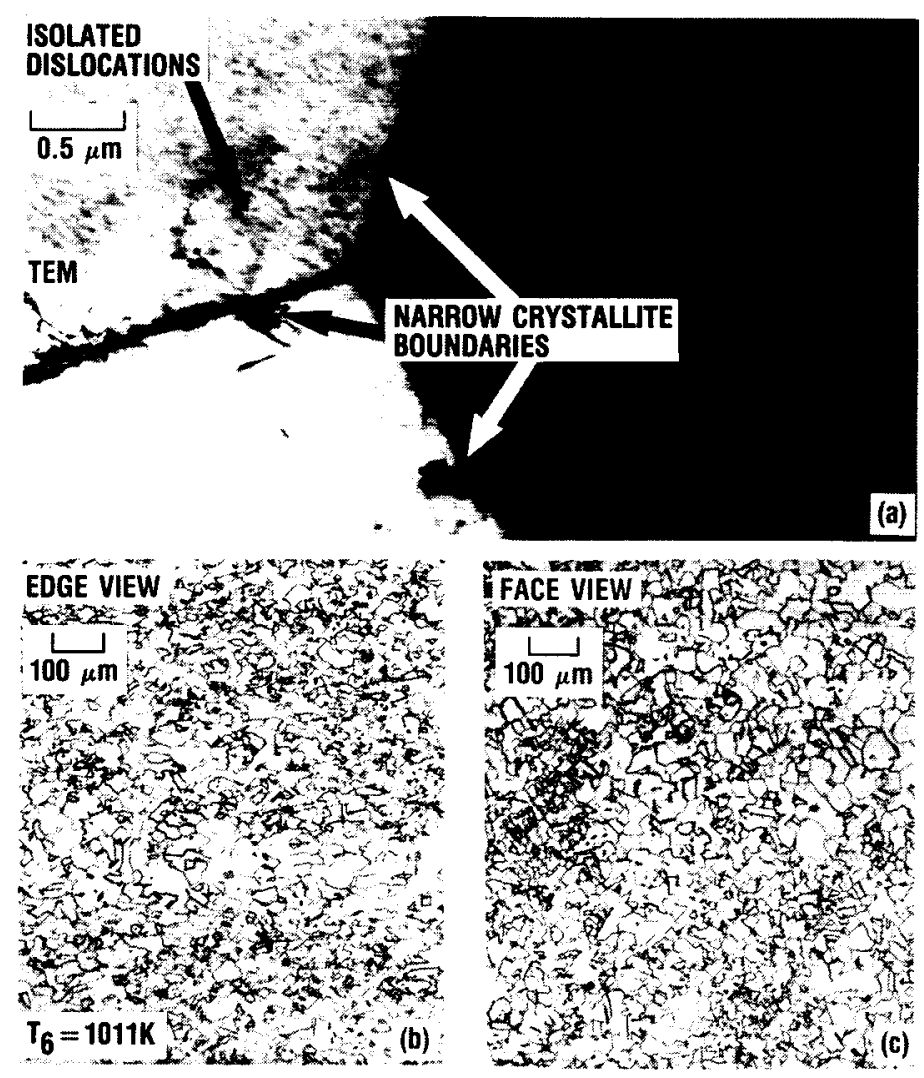

FigURE 8. - TRANSMISSION ELECTRON MICROGRAPH, AND EDGE AND SIDE METALLOGRAPHIC VIEWS OF SAMPLE ANNEALED AT $1011 \mathrm{~K}\left(\mathrm{~T}_{6}\right)$. 


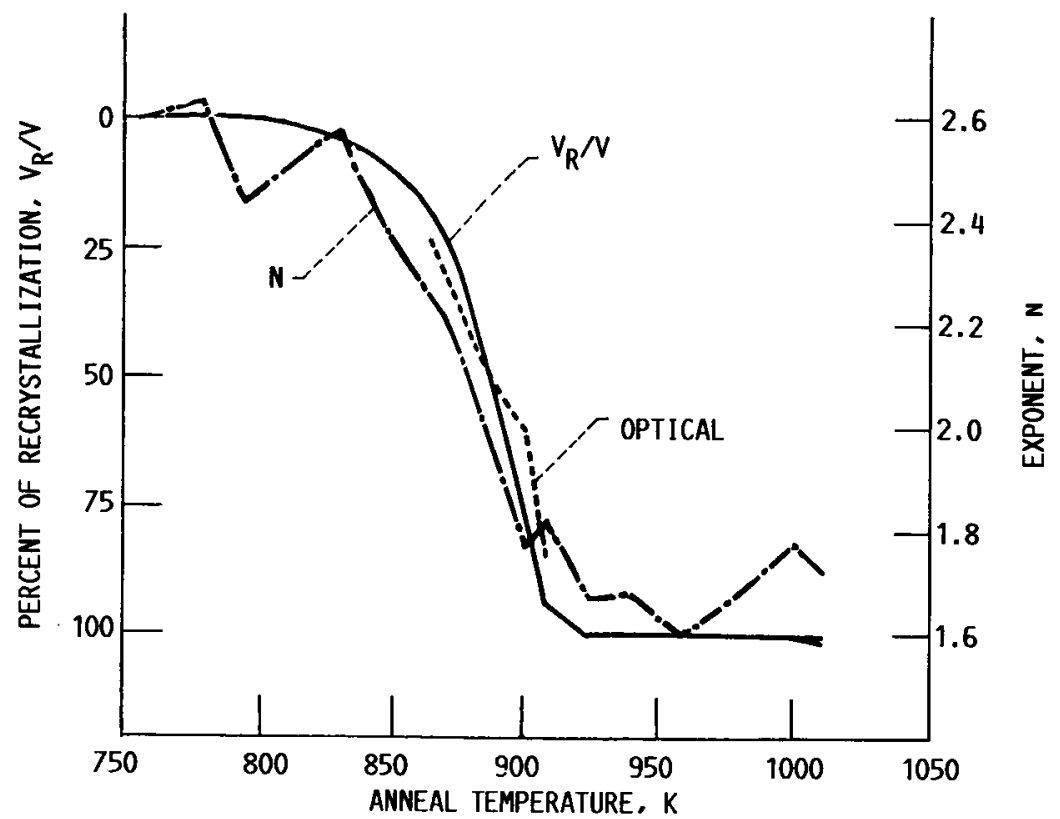

Figure 9. - RECRYSTALlization PERCENT $V_{R} N$ DETERMined BY USE OF EQUATION (3) (SOL ID CURVE)? LIGHT OPTICAL METALLOGRAPHIC TECHNIQUES (DOTTED CURVE) AND CALCULATED EXPONENT N (DASH-DOTTED CURVE) AS A FUNCTION OF ANNEALING TEMPERATURE.

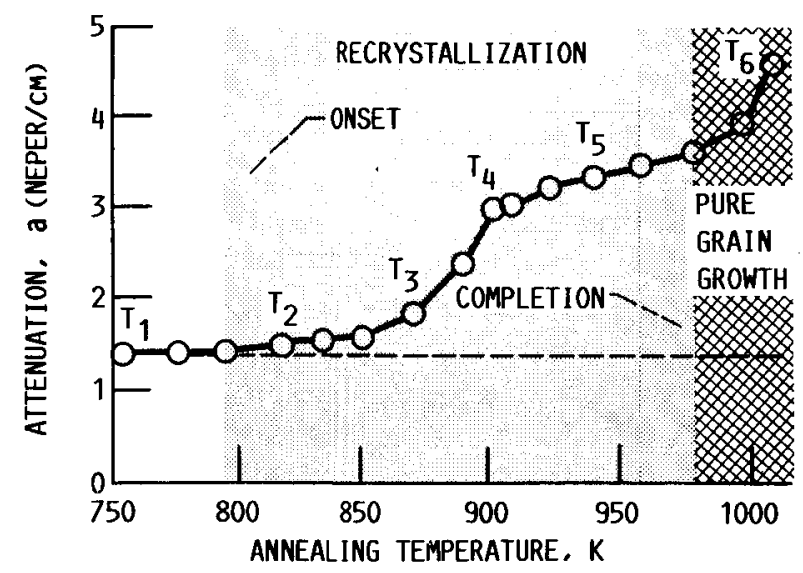

Figure 10. - ATTENUATION AS A FUNCTION OF ANNEAL ING

TEMPERATURE AT $40 \mathrm{MHZ}$. THE LIGHT SHADING IN THE FIGURE INDICATES ACOUSTIC IDENT IF ICATION OF THE TEMPERATURE RANGES FOR ONSET AND COMPLETION OF RECRYSTALLIZATION. THE DARK SHADING INDICATES THE RECRYSTALL IZATION TEMPERATURE RANGE. THE CROSS-HATCHED REGION INDICATES THE

ONSET OF PURE GRAIN GROWTH. THE TEMPERATURE

LABELS T 1 TO $T_{6}$ REFER TO THE DATA SHOWN IN

FIGURES 3 TO 8, RESPECTIVELY. 


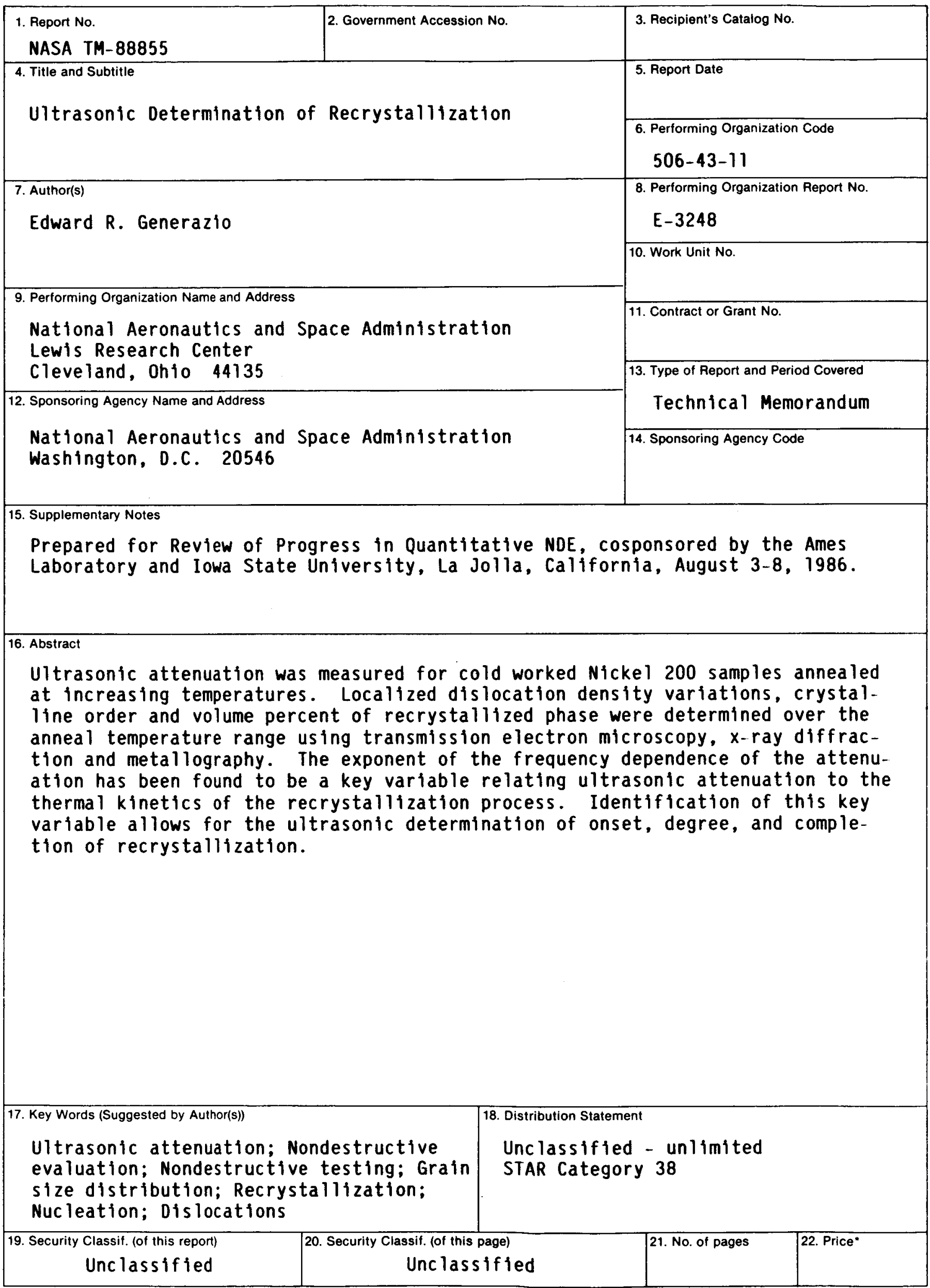

